\title{
The Global Blue Water Use for the Dutch Diet and Associated Environmental Impact on Water Scarcity
}

\author{
Hollander Anne ${ }^{1}$, Vellinga Reina Elisabeth ${ }^{1,2}$, Valk Elias de ${ }^{1}$, Toxopeus Ido ${ }^{1}$, Kamp Mirjam van de ${ }^{1}$, \\ Temme Elisabeth Helena Maria ${ }^{1,2}$ \\ ${ }^{1}$ National Institute of Public Health and the Environment (RIVM), Bilthoven, The Netherlands \\ ${ }^{2}$ Department Agrotechnology and Food Sciences, Wageningen University and Research Centre, Wageningen, The Netherlands
}

Email address:

anne.hollander@rivm.nl (H. Anne), reina.vellinga@rivm.nl (V. R. Elisabeth), elias.de.valk@rivm.nl (V. Elias de), liesbeth.temme@rivm.nl (T. E. H. Maria)

\section{To cite this article:}

Hollander Anne, Vellinga Reina Elisabeth, Valk Elias de, Toxopeus Ido, Kamp Mirjam van de, Temme Elisabeth Helena Maria. The Global Blue Water Use for the Dutch Diet and Associated Environmental Impact on Water Scarcity. World Journal of Food Science and Technology. Vol. 5, No. 1, 2021, pp. 10-18. doi: 10.11648/j.wjfst.20210501.13

Received: November 25, 2020; Accepted: December 8, 2020; Published: January 28, 2021

\begin{abstract}
Agriculture is responsible for around 70\% of global water withdrawal, making it the largest consumer of freshwater. Globally, freshwater is a scarce resource, and there is increasing risk that current water use is crossing the planetary boundary, meaning that humanity is using more freshwater than nature can replenish. Beside the amount of water used for the production of food, also the location of water use is of importance to identify local water scarcity. In this study we determined and analyzed the blue water use for the Dutch diet. Also, we provide an indication of the the spatial distribution in water use, related to water scarcity. The blue water use per person for the average diet of the Dutch adult population aged 19-79 years as calculated in this study was $160 \mathrm{l} /$ day $\left(=57 \mathrm{~m}^{3} /\right.$ year $)$ for men and $153 \mathrm{l} /$ day $\left(=56 \mathrm{~m}^{3} /\right.$ year $)$ for women. Non-alcoholic beverages were the most important contributor to water use for the diet of men as well as women. Fruits were the second most important contributor to water use for the diet of women (particularly oranges, tangerines, strawberries and bananas), and the third most important for men. Meat was the second most important contributor for men (particularly chicken fillet and beef meat) and the third for women. About one third of the blue water use for the Dutch diet takes place in countries where 30 to 70 times less available water remaining per area than the world average. This means that water scarcity is relatively high in those countries compared to the world's average. The main countries of origin of the water used for food production for the Dutch population we identified were Spain, the Netherlands itself, South Africa, Chile, India and USA. Products with ingredients from Spain are several types of greenhouse vegetables, citrus fruits and juices. To lower the environmental impact related to blue water use, for the Dutch situation we conclude that beside reducing meat and dairy consumption, consuming more Dutch fruits like apples and pears, and reducing imports of fruits and nuts from e.g. Spain, Chile and USA, are relatively easy changes that will have a positive effect on the global water scarcity impact. Also, reducing the consumption of non-alcoholic beverages like coffee, soft drinks and juices, and increasing the use of tap water, is recommended to lower the Dutch blue water use within a healthy diet.
\end{abstract}

Keywords: Blue Water Use, Water Scarcity, AWARE, Dutch Food Consumption

\section{Introduction}

Agriculture is responsible for around $70 \%$ of global water withdrawal [1] and for around $90 \%$ of the global and European water footprints [2, 3], making it the largest consumer of freshwater [4]. Globally, freshwater is a scarce resource, and there is increasing risk that current water use is crossing the planetary boundary, meaning that humanity is using more freshwater than nature can replenish in a year ${ }^{4}$. Current water use causes depletion of freshwater sources, which results in damage to ecosystems on a local level. Whether local water use has a negative environmental impact depends on the amount of water used in relation to local water availability or scarcity [5]. The Netherlands suffers relatively little from water scarcity, but Dutch food consumption does have a relatively high external water footprint, which means that it depends for the larger part on 
freshwater resources elsewhere [2]. In this way, foods consumed in the Netherlands may cause environmental damage through water use in other parts of the world.

The environmental impact of the Dutch diet has previously been assessed for the indicators greenhouse gas emissions, land use, and blue water use [6-8]. While the indicators greenhouse gas emissions and land use are strongly correlated for foods consumed in the Netherlands, the correlation of greenhouse gas emissions with water use is significantly lower [8, 9]. Some foods, for example certain fruits and nuts, are associated with relatively low greenhouse gas emissions and land use, but relatively high water use [10]. Moreover, former studies on the environmental sustainability of the Dutch diet did not consider the countries of origin of the blue water in relation to water scarcity in those areas. To gain a more comprehensive insight in the various aspects of the environmental impact of Dutch food consumption, it is therefore necessary to consider water use and water scarcity associated with the diet.

Many previous studies on freshwater use for food production and consumption have used the water footprint methodology [11] with FAO Food Balance Sheets to calculate the water need of food consumption at the level of raw agricultural products $[12,13]$. Linking water use with food consumption at the level of raw agricultural products means that results are obtained on an aggregate level (e.g. flour, bread and pasta are all quantified as wheat equivalents). Boulay et al. [14] have proposed a methodology to assess the environmental impacts of freshwater use in Life Cycle Assessment (LCA). LCA offers the advantage of being able to estimate differences in the blue water use of individual foods based on the same raw agricultural product, with the ability to trace water use back to the various life cycle stages including processing, packaging, storage and preparation. This proposed methodology was the result of an large exercise to which many scientists world-wide had contributed. Currently, only blue water use (surface and groundwater) is included in the LCA methodology [14], and not green water (precipitation and soil moisture) or grey water (amount of polluted water).

Beside the amount of water used for the production of food, also the location of water use is of importance to determine the potential environmental effects i.e. Water extraction from relatively water scarce areas will usually cause more environmental damage than water extraction from water rich areas.

The main aim of this study was to determine and analyze the blue water use for the Dutch diet using LCA methodology and self-reported food consumption data for adults aged 19-79 years. Moreover, an indication was given for the relation between the spatial distribution in water use for of Dutch food production to water scarcity in the production areas.

\section{Materials and Methods}

\subsection{Food Consumption Data and General Participant Information}

Food consumption data were obtained from the Dutch
National Food Consumption Survey (DNFCS) 2012-2016, described in more detail elsewhere [15]. Food consumption was measured using two non-consecutive 24-hour dietary recalls that were conducted by dietitians on independent days about four weeks apart with use of the GloboDiet software [16]. The study population was a representative sample of the Dutch population with respect to age, gender, region, degree of urbanization and educational level. The overall response was $65 \%(n=4313)$. For this study, adult men and women aged 19-79 years old were included. Calculations were based on 2078 individuals (1043 men and 1035 women). Food consumption data were linked to the composition of foods in the Dutch Food Composition Table (NEVO-online 2016/5.0) [17] in order to calculate energy intake.

A general questionnaire was used to cover various sociodemographic and lifestyle factors as described by Van Rossum et al. [15]. Height (in $\mathrm{m}$ ) and weight (in $\mathrm{kg}$ ) were self-reported during the first 24-hour recall. Body mass index (BMI) was determined as the average body weight divided by average height squared $\left(\mathrm{kg} / \mathrm{m}^{2}\right)$.

\subsection{Water Use Data}

Blue water use (direct and indirect) in $\mathrm{m}^{3}$ (and recalculated into liters) associated with foods consumed was estimated using LCA with a functional unit of $1 \mathrm{~kg}$ product at plate or drink. Blue water use is defined as the total amount of water sourced from surface or groundwater resources that is evaporated, incorporated into products, transferred to other watersheds or disposed into the sea. The LCAs had an attributional approach and an hierarchist perspective. Life Cycle Impact Assessment (LCIA) was performed using ReCiPe 2016 [18] and SimaPro software (Pre Consultants; version 8.52) (PRe Consultancy B. V., Amersfoort, the Netherlands). Life Cycle Inventory (LCI) data from Blonk Consultants based on Agri-Footprint [19] representative for Dutch situations were used and are referred to as primary data [20]. All life cycle stages from cradle till plate were included in the analyses, including phases from primary production, processing, primary packaging, distribution, retail, supermarket, storage, preparation by the consumer (e.g. cooking) and incineration of packaging waste. Transport between all phases, except from retail to the consumer was included. Food waste was included by using food group specific percentages for avoidable and unavoidable food losses throughout the food chain. Land use change was included as direct land use change [21]. Disinfectants and refrigerants used in the processing phase, secondary and tertiary packaging materials, and surface albedo change were not included. Economic allocation was applied when production processes lead to more than one food product, except for milk, where physical allocation was used. Blue water use was regionalized on country level.

The LCA data were available for 242 foods (primary data) that were either frequently consumed or that had a relatively high water use. Extrapolations were made to all other 
( $n=1854$ ) foods consumed in the DNFCS 2012-2016, based on similarities in type of food, production method, and ingredient composition by expert judgement.

\subsection{Water Scarcity Data}

The AWARE (Available Water Remaining) factors as proposed by Boulay et al. [14] are used as an indicator for water scarcity (version 2019 February). The index ranges from 0.1 to 100 and is based on the relative available water remaining per area once the demand of humans and aquatic ecosystems has been met. A value of 1 corresponds to the world average, and values below 1 represent regions where more available water is remaining per area than the world average. Values above 1 indicate that less available water is remaining per area. For example, a value of 10 indicates that in that region there is 10 times less available water remaining per area than the world's average, and a value of 0.1 indicates that in that region there is 10 times more available water remaining than the world's average. Annual country level values for water scarcity were used. The AWARE methodology distinguishes between water use for agricultural and non-agricultural purposes, and for a combination of both (so-called 'unknown' factors). Total water use per $\mathrm{kg}$ of a food product as calculated in the LCAs for this study is a combination of agricultural and non-agricultural use, and therefore the "unknown" AWARE factors were used. Countries were divided into six categories based on their AWARE factor: 0.1-1, 1-2, 2-10, 10-30, 30-70, and 70-100.

\subsection{Calculating the Blue Water Use for the Dutch Consumption}

Daily average food intake of the Dutch population by food group was calculated over two consumption days for 1043 men and 1035 women aged 19-79 years. The blue water use of the average Dutch diet was calculated by multiplying the average amount consumed per day of each food with the amount of blue water used for the production of $1 \mathrm{~kg}$ of that food. Moreover, the countries of origin of the water used were identified, and their relative contribution to the total blue water use was assessed. The AWARE factors of the countries contributing to the Dutch food consumption were identified and coupled to the relative contribution in water use.

Descriptive statistics (mean and standard deviation) were calculated for the entire population, and for men and women separately. A weighting factor was used for demographic properties, season (at first recall day) and a combination of both recall days (week or weekend). All calculations were performed using SAS software (version 9.4, SAS Institute Inc., Cary, NC, USA).

\section{Results}

\subsection{Participant Characteristics and Food Consumption Data}

Table 1 shows the general characteristics of the study population and the daily energy intake and food consumption calculated as the average of the two 24-hour recalls. More than half of the men and women included were overweight, most had intermediate of high education levels. As a result of the sampling design, participants were spread evenly over the different age categories.

The mean reported intake of kilocalories per day is 2543 for men and 1860 for women. People consume about 1877 (men) to 1972 (women) grams of non-alcoholic beverages per day, of which about $70 \%$ can be attributed to water and coffee/tea, whereas the remaining is attributed to juices, soft drinks and dairy drinks. On average, men consume 268 grams of alcoholic beverages per day, and women 75 , with a standard deviation in the study group of 550 (men) and 193 (women). The consumption of cheese, dairy and vegetables is comparable for men and women, with an average of grams of 40 resp. 32 gram cheese per day, and 327 resp. 275 grams of dairy. The daily consumption of vegetables, legumes and peas ranges is about 150 grams. Daily fruit consumption is higher for women than for men (average for women is 134 grams and for men 108 grams), whereas men consume more potatoes and grains (323 grams versus 230 grams for women). Also meat consumption is higher for men: they report a mean daily consumption of 121 grams whereas women report a mean daily intake of 83 grams. The reported daily consumption of nuts and meat replacers is low.

Table 1. Participant characteristics and food consumption data: daily intake of energy and different food products.

\begin{tabular}{llll}
\hline & Total population 19-79 $\mathbf{~ r r}$ & Men 19-79 $\mathbf{~ y r}$ & Women 19-79 $\mathbf{~ y r}$ \\
\cline { 2 - 4 } & $\mathbf{( n = 2 0 7 8 )}$ & $\mathbf{( n = 1 0 4 3 )}$ & $\mathbf{( n = 1 0 3 5 )}$ \\
\hline General characteristics (\%) & & & 12,3 \\
Age 19-30 yr & 24,8 & 12,5 & 12,7 \\
Age 31-50 yr & 25,1 & 12,5 & 12,4 \\
Age 51-70 yr & 25,1 & 12,7 & 12,4 \\
Age 71-79 yr & 24,9 & 12,5 & 2 \\
BMI - Underweight & 2 & 2 & 43 \\
BMI - Normal weight & 44 & 45 & 32 \\
BMI - Overweight & 35 & 37 & 23 \\
BMI - Obese & 19 & 16 & 25 \\
Education level ${ }^{1}$ - Low & 21 & 18 & 43 \\
Education level - Intermediate & 42 & 42 & 33 \\
Education level - High & 37 & 41 & \\
\hline
\end{tabular}




\begin{tabular}{lllllll}
\hline Daily energy and food intake $^{2}$ & Mean & Stdev & Mean & Stdev & Mean & Stdev \\
\hline Energy (kcal) & 2200 & 929 & 2543 & 954 & 1860 & 656 \\
Potatoes and grains (g) & 276 & 145 & 323 & 150 & 230 & 112 \\
Vegetables, legumes and peas (g) & 150 & 131 & 147 & 121 & 152 & 139 \\
Fruits (g) & 121 & 167 & 108 & 154 & 134 & 177 \\
Nuts (g) & 11 & 29 & 14 & 34 & 8 & 22 \\
Meat (g) & 102 & 88 & 121 & 93 & 83 & 75 \\
Meat replacers (g) & 2 & 13 & 2 & 16 & 1 & 10 \\
Dairy (g) & 301 & 321 & 327 & 343 & 275 & 294 \\
Cheese (g) & 36 & 41 & 40 & 45 & 32 & 36 \\
Fish (g) & 19 & 53 & 19 & 57 & 18 & 12 \\
Eggs (g) & 14 & 29 & 15 & 32 & 952 & \\
Coffee and tea (g) & 870 & 711 & 814 & 658 & 79 \\
Juice and softdrinks (g) & 356 & 542 & 422 & 606 & 291 & 754 \\
Water (g) & 661 & 844 & 566 & 819 & 755 & 457 \\
Alcholic beverages (g) & 171 & 431 & 268 & 550 & 75 & 852 \\
Fats and oils (g) & 24 & 20 & 28 & 22 & 19 & 193 \\
Sweet and savory snacks (g) & 93 & 97 & 106 & 110 & 79 & 17 \\
Broth, sauces and condiments (g) & 105 & 155 & 108 & 154 & 100 & 80 \\
\hline
\end{tabular}

${ }^{1}$ low=no education/primary education/lower vocational education/advanced elementary education; intermediate=intermediate vocational education/higher general secondary education; high=higher vocational education/university.

${ }^{2}$ Based on the average of two 24-hour recalls.

\subsection{Blue Water Use}

The blue water use per person for the average diet of the Dutch adult population aged 19-79 years as calculated in this study was $160 \mathrm{l} /$ day $\left(=57 \mathrm{~m}^{3} /\right.$ year $)$ for men and $153 \mathrm{l} /$ day $\left(=56 \mathrm{~m}^{3} /\right.$ year $)$ for women. Non-alcoholic beverages were the most important contributor to water use for the diet of men as well as women (see Table 2), thereby orange juice, tea and coffee being the individual beverages contributing most. Fruits were the second most important contributor to water use for the diet of women (particularly oranges, tangerines, strawberries and bananas), and the third most important for men. Meat was the second most important contributor for men (particularly chicken fillet and beef meat) and the third for women.

Table 2. Total daily blue water use and blue water use per food group for the total population, as well as for men and for women separately.

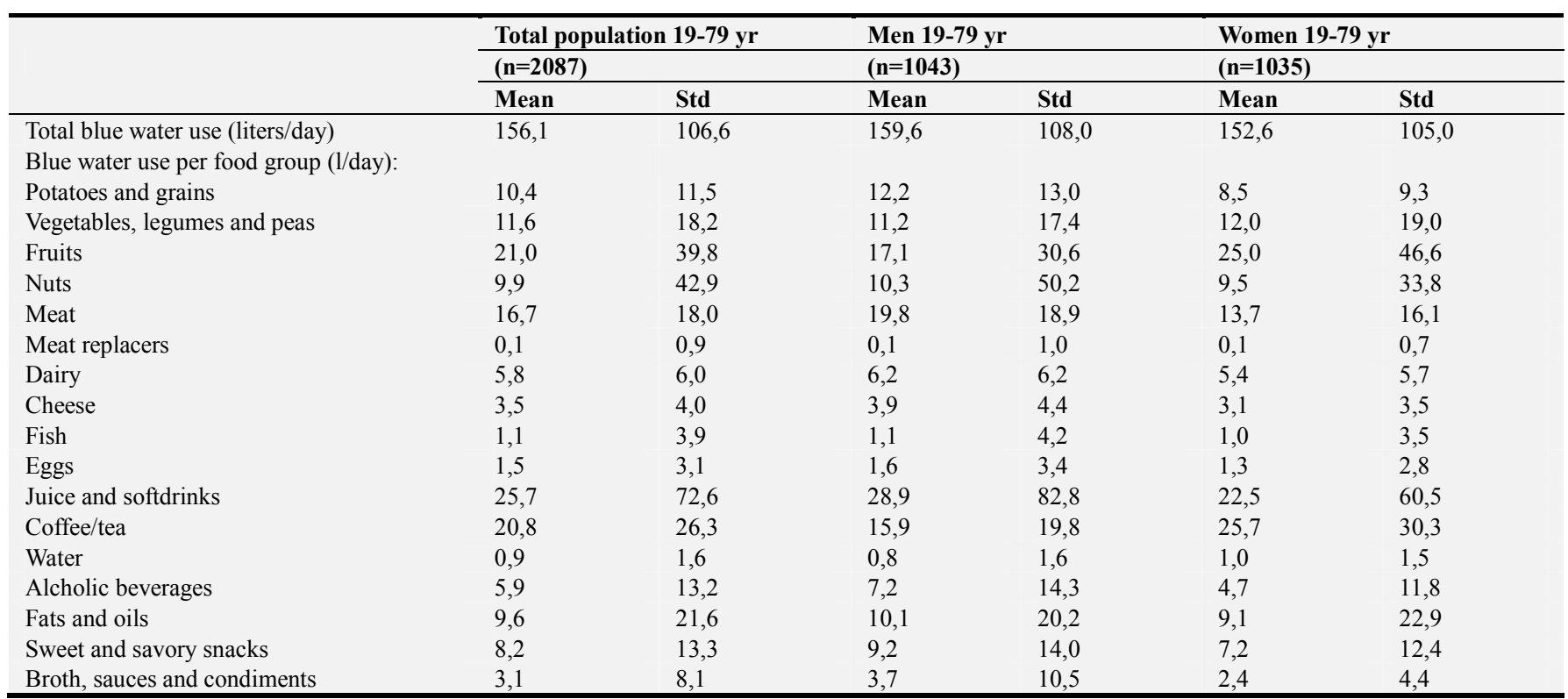

\subsection{Water Scarcity}

In Table 3, an overview is given of the eleven main countries of origin providing water for the Dutch food consumption (all countries with more than $2 \%$ contribution), as well as the AWARE-factors corresponding with these countries according to Boulay et al. This information was also visualized in Figure 1. As can be seen from Table 3 and Figure 1, the main countries of origin of the water used for food production for the Dutch population that were identified were Spain, the Netherlands itself, South Africa, India and USA. Products with ingredients from Spain for which most water is consumed for the Dutch consumption, are several types of greenhouse vegetables, citrus fruits and 
juices. Fruits and juices are also the main source of water use in South Afrika and Chile. Spain and Chile have a high AWARE factor, indicating that water is relatively scarce in these countries. The Netherlands has an AWARE factor of 1.2 , which is quite low. Ten percent of total blue water use for the diet of people in the Netherlands takes place in the Netherlands itself, being slightly higher for women than for men. Water consumption in the Netherlands itself is mainly due to the production of (red) fruits, potatoes and potato products. Water use in India (and also Malawi) for the Dutch food consumption can be mainly ascribed to tea. Two countries from Northern Africa (Egypt, Morocco) are in the top-10 of countries 'exporting' water to the Netherlands. Of all countries, these have the highest AWARE-factors, indicating severe water scarcity. The water use can be mainly ascribed to citrus fruits, vegetables (like beans) and nuts. Products with ingredients from the USA that contribute most are several meat products and those in which almonds were included (such as marzipan). The country-average AWARE factor of USA is medium high. The relatively high contribution of meat products was caused by the production of feed in the USA that are imported to the Netherlands.

Table 3. List of eleven countries with highest water consumption for the average Dutch diet (in l/pp/day).

\begin{tabular}{lllll}
\hline \multirow{2}{*}{ Country } & Blue water use for the Dutch diet & Contribution per country & AWARE factor \\
\cline { 3 - 4 } & I/pp/day & \% & - \\
\hline 1 & Spain & 19,18 & $12 \%$ & 79,3 \\
2 & The Netherlands & 16,05 & $10 \%$ & 1,2 \\
3 & South Africa & 12,80 & $8 \%$ & 38,4 \\
4 & India & 10,75 & $7 \%$ & 29,8 \\
5 & United States of America & 9,87 & $6 \%$ & 33,1 \\
6 & Egypt & 8,22 & $5 \%$ & 96,0 \\
7 & Malawi & 8,04 & $5 \%$ & 5,5 \\
8 & France & 5,29 & $3 \%$ & 8,2 \\
9 & Marocco & 4,17 & $3 \%$ & 87,4 \\
10 & Chile & 3,93 & $3 \%$ & 81,4 \\
11 & China & 3,64 & $2 \%$ & 42,5 \\
& Total & 101,94 & $64 \%$ & \\
\hline
\end{tabular}

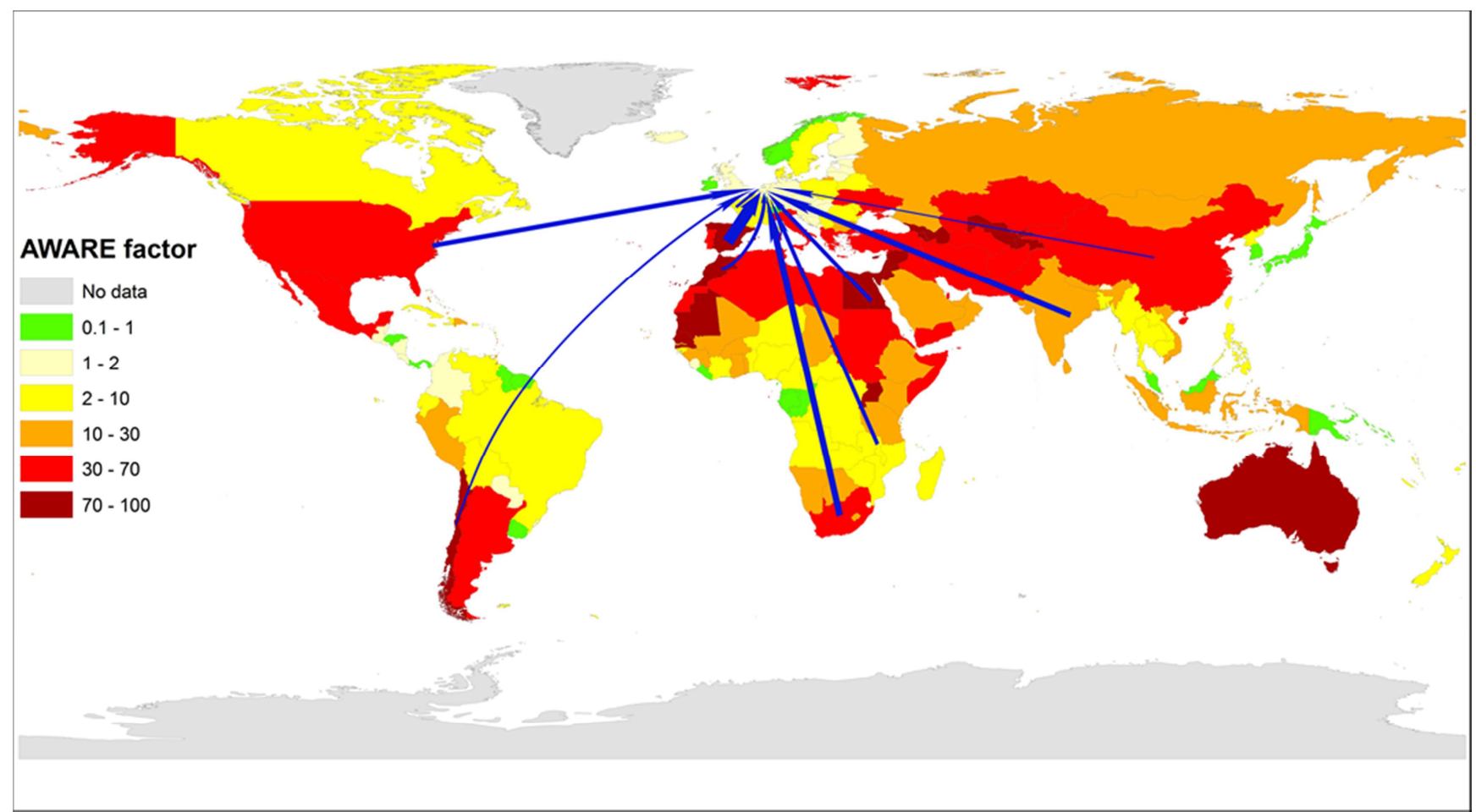

Figure 1. Overview of the AWARE categories per country worldwide. The arrows represent the top ten countries in the world 'exporting' blue water to The Netherlands via the food chain. The thicknesses of the arrows indicate the relative contribution of the countries, as given in Table 2.

In Figure 2, the cumulative contribution of the different AWARE categories to the total water use for food consumption of the Dutch population (19-79 year) is given, both for the total population and for men and women specifically. About one third of the blue water use for the
Dutch diet takes place in countries where 30 to 70 times less available water remaining per area than the world average. This means that water scarcity is relatively high in those countries compared to the world's average. Countries with more available water remaining per area than the world 
average contribute least to total blue water use for the Dutch diet. For about $17 \%$ of the blue water used for the Dutch diet, the exact source is unknown. This is e.g. caused by the fact that the country of origin of packaging materials is often unknown, as is the origin of the water use. The same applies for some other general processes in the LCA models.

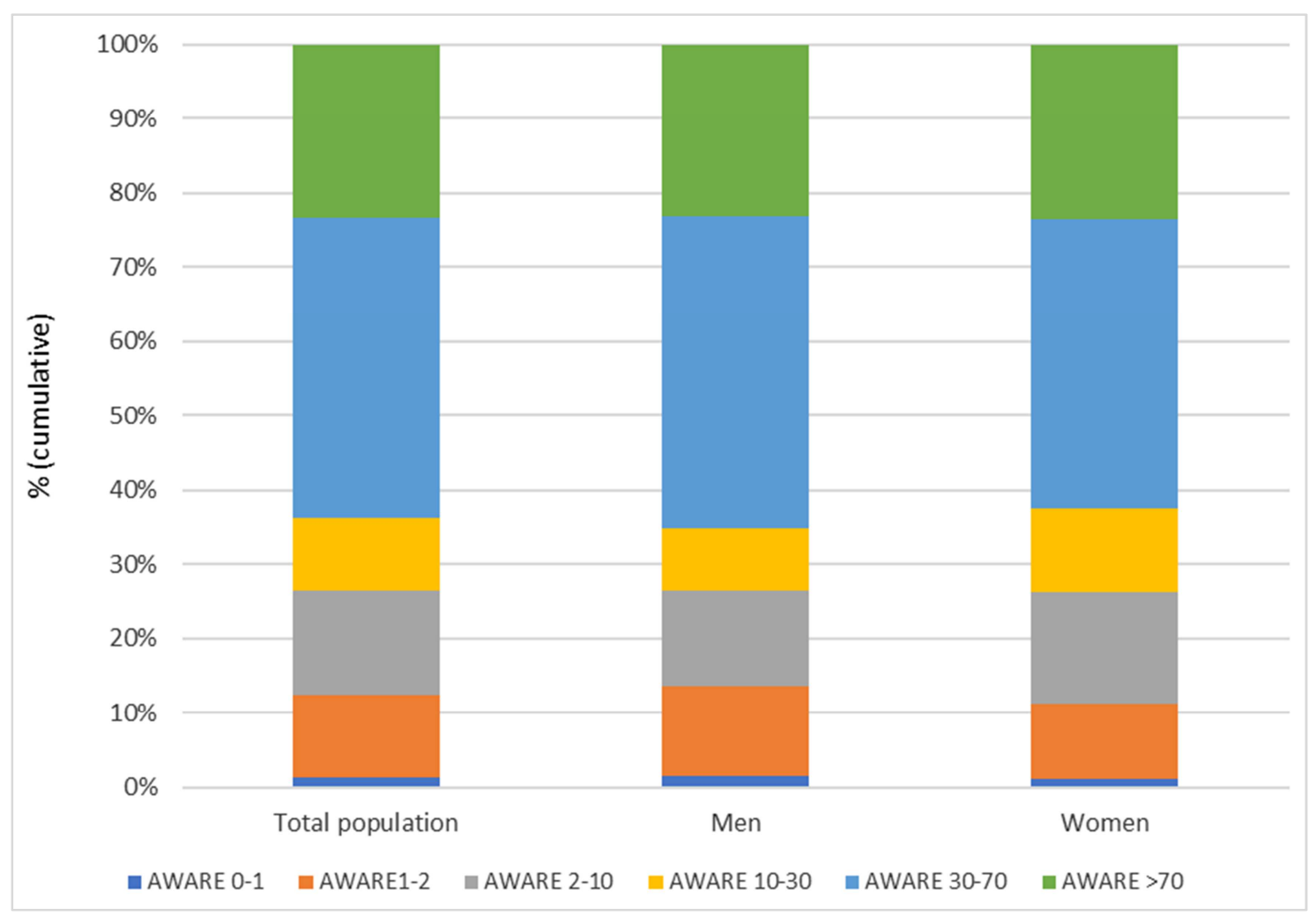

Figure 2. Cumulative contribution of the different AWARE categories to the total water use for the Dutch food consumption. Values are given for the average Dutch diet of the total adult population (19-79 yr), as well as for men and women separately.

\section{Discussion}

In this study, we calculated the blue water use and explored the environmental impact due to water scarcity for the diet of Dutch adults aged 19 to 79 years [HERE WE DELETED SOME TEXT, MOVED TO CONCLUSION].

\subsection{Methodological Limitations}

Although we performed the analyses as detailed as possible, a number of assumptions had to be made and uncertainties exist, both on the dietary data, and on the production processes of foods. Even though the two 24hour recalls in the DNFCS 2012-2016 are sufficiently valid to measure food and nutrient intakes [22], it is expected that some misreporting of energy intake occurs [15, 23]. Because the precise extent to which misreporting occurs is unknown, the results in this study have not been corrected for misreporting.

Concerning the life cycle analysis on the food products, one assumption was that the processing of primary food products always occurs in The Netherlands. Often this is indeed the case, but in some cases, this assumption may give an overestimation of water use within The Netherlands and an underestimation of water use abroad. However, for almost all food products, the primary production phase accounts for the largest part of the total water consumption, meaning that this assumption will most likely not significantly affect the results. Also, per food product, the countries were selected that covered together at least $70 \%$ of the market mix available on the Dutch market. Some minor countries exporting to The Netherlands were thus excluded. In the LCIA calculations, for about $15 \%$ of the food products primary LCA data were available (representing $>80 \%$ of the total consumption in the Netherlands), the remaining part was based on extrapolations. This was done as good as possible based on similarities and recipes between products, but some differences between products and their life cycle chains, which were now considered similar, can be disregarded. Finally, we have focused on blue water use, neglected green water consumption, which may also cause environmental impact.

Another issue is that we performed the analysis on a country level. For most countries, this spatial scale was detailed enough. However, the spatial variability in water scarcity within a country may be high, which would plea for a more regionalized analysis. This omission was already recognized by Pfister et al. (2009) [24], who concluded that regionalization on a country level proved to be not specific enough for large countries. They illustrated this for the USA, which has a moderate AWARE factor on a country level, but copes with severe water scarcity problems in specific regions, 
e.g. California (nuts production). Therefore, large countries with varying climatic zones, such as the USA, India, and China should preferably be assessed on a watershed level. Boulay et al. [14] identified Sub-Saharan Africa, Australia, Central Asia, and USA as the regions showing largest regional differences in water scarcity indexes compared to the averages. Unfortunately, for the current study, such data on watershed level were not available [14]. The same applies for temporal (annual) variability, which was also neglected in this study. About $50 \%$ of the world water consumption is located in regions where the variation between the most different month (high or low) and the annual value is larger than 50, emphasizing the importance of temporal resolution. Differences are especially seen in Central Asia, Spain, North and South Africa, Western Australia, Middle East, and parts of China [14]. It would be valuable to incorporate more spatial and temporal detail in future studies on blue water uses of food.

\subsection{Blue Water Use}

Our study shows that, by weight, non-alcoholic beverages make up the largest part of the diet, and this is also the food group contributing most to total blue water use. Per kilogram of product, the blue water use of nuts and seeds $\left(2.7 \mathrm{~m}^{3}\right)$, fats and oils $\left(0.63 \mathrm{~m}^{3}\right)$, fruit $\left(0.47 \mathrm{~m}^{3}\right)$ and meat $\left(0.23 \mathrm{~m}^{3}\right)$ is relatively high. The high use per kilogram for these food groups are reflected in the total blue water use of the Dutch diet for meat, dairy and fruits, however not for nuts and seeds. Since the consumption of nuts in the study population was low, their total contribution to the blue water use of the Dutch diet was not significant. The relatively high water use for meat consumption in The Netherlands is mainly caused by the fact that a lot of water is used for feed production in among others, the USA. The reported daily intake of meat replacers was low, therefore they hardly contributed to the total calculated water use. The total use for men is slightly higher than for women, which can be explained by the larger amount of food consumption in gram and energy, as well as a relatively high meat consumption compared to women. For women, the higher consumption of fruits with respect to men (which have a relatively high water consumption per $\mathrm{kg}$ and per caloric intake) results in a relatively high blue water use for this food group.

Our results concerning the blue water use of the Dutch diet, and the main food products contributing to water use are more or less in line with previous studies performed in The Netherlands and in other countries. For The Netherlands, Van Oel et al. (2009) [25] calculated the water use related to the consumption of agricultural goods. They reported a contribution of inland water to the total water use of $11 \%$ (this study 8\%), and they also concluded that large part of the total water use could be attributed to livestock products, coffee and tea.

Harris et al., (2019) performed a review on globally available studies on the blue and green water footprint of diets [26]. The available evidence collected in that study suggests that, on average, European dietary patterns have the highest green water footprints, whereas Asian dietary patterns have the highest blue water footprints, with a median of 382 liters per day per capita. European dietary patterns have an average blue water footprint of 241 liters per capita per day, with a range of 159-266 liters per capita per day. The value calculated for the Dutch blue water use in our study (156 liters per capita per day) is slightly lower than the range reported by Harris et al., but seems reasonable compared to the other studies reviewed by Harris et al [26]. Besides, they conclude that on a global scale, goods of animal origin, cereals, fruits, nuts, and oils are major contributors to the water footprints (blue and green) of diets. In line, Hoekstra (2012) reported that the consumption of animal products contributes to more than $25 \%$ of the total water footprint of humanity [2]. These findings generally correspond with ours.

We also compared our study to some other single-country studies. For the German diet (as measured in 2006), Meier and Christen [27] found that the total blue water use was 28.4 $\mathrm{m}^{3}$ per person per year (or about 80 liters per capita per day). This number is significantly lower than was found in this study for the Dutch diet. However, Meier and Christen omitted the food group of alcoholic and non-alcoholic drinks. If we recalculate the value for The Netherlands without drinks, we obtain a value of about 100 liters per capita per day for adults aged 19-79 year, which is $20 \%$ more than the German study estimated. In line with our study, the German study reported that fruits were important contributors to the blue water use of their diet. However, they also found a high contribution of nuts and seeds, which is not reflected in our study. This difference can be mainly explained by the higher consumption of those products in Germany, as well as to differences in estimation methods. In the USA, the current blue water use is estimated 40 billion $\mathrm{m}^{3}$ per year, which corresponds to about 122 liters per capita per day [28]. This relatively low value can be mainly attributed to the low consumption of fruits, which have a relatively high blue water use per kilogram or caloric intake. Tom et al. [28] indicate that if the American population would shift its diet towards the current healthy dietary guidelines, the blue water use will increase due to increased consumption of fruits and vegetables, even if the total caloric intake will be reduced conform the guidelines.

\subsection{Water Scarcity}

Many studies on water use for food products only consider the amount of water consumption in the life cycle of products, thereby neglecting the location of origin of the water. In this study, we also studied the countries of origin of the water and used the AWARE factors of Boulay et al. [14] as a measure to indicate whether water is scarce or not. Such an analysis provides much more information on the potential environmental and human damage the water consumption may cause, and is therefore considered a valuable addition. This was also identified e.g. by Pfister et al. (2009) [24] who stated that needed water quantities and impact factors vary strongly as a function of location, leading to high differences 
in the total damages from water consumption in different countries. From this study, we can conclude that only a minor part of the total water needed for the Dutch food consumption is of Dutch origin, so more than $90 \%$ of the water is 'imported'. Moreover, we identified that a significant part of this water is imported from countries that have a high level of water scarcity according to the AWAREmethodology. This means that the environmental impact of food production for the Dutch market due to water consumption in those countries may be relatively large. Examples are Spain, Egypt, Morocco, and the food products contributing most are (citrus) fruits, vegetables and livestock products (particularly feed).

\subsection{Recommendations for Reducing Water Scarcity Impact by Shifting Diets}

It is generally known and also communicated to the public in different media, e.g EAT Lancet report [29] that reducing the intake of animal-based foods by plant based foods will lead to a healthier as well as more sustainable diet. Considering climate change as one of the important sustainability indicators, several scientific studies substantiate this theorem, e.g. Aleksandrowicz et al. [30]. Several other studies show that the same is true if we concern water use and water scarcity as sustainability indicators, e.g. Hoekstra, Jalava et al. and Davis et al [2, 31, 32]. For example, Hoekstra concluded that in industrialized countries, moving toward a vegetarian diet can reduce the food-related water use of people by $36 \%$. However, the production of fruits and nuts, although relatively low in the sustainability indicators 'climate change' and 'land use', often corresponds with high blue water use, also in water scarce areas [33].

From our study, partly, a similar conclusion can be drawn for the Dutch situation. We state that, in general, plant based foods often have a lower blue water use than animal based foods. This for sure applies if we compare the protein-rich plant based foods with animal based foods, but this does not apply for all foods. Some plant-based foods do have a relatively high blue water use per kg product, such as several fruits and nuts. Thereby it is important to see that these foods are often imported into The Netherlands from areas with a relatively high water scarcity. Examples are citrus fruits from Spain and Morocco and almonds from the USA. To reduce the environmental impact of water use, one should therefore prefer fruits and nuts from areas with a low water scarcity. For the Dutch situation this means that, beside reducing meat and dairy consumption, consuming more Dutch fruits like apples and pears, and reducing imports of fruits and nuts from e.g. Spain, Chile and USA, are relatively easy changes that will have a positive effect on the global water scarcity impact. Also reducing the consumption of non-alcoholic beverages like coffee, soft drinks and juices, and increasing the use of tap water, is recommended to lower the Dutch blue water use within a healthy diet.

\section{Conclusion}

The blue water use per person for the average diet of the Dutch adult population aged 19-79 years as calculated in this study was $160 \mathrm{l} /$ day $\left(=57 \mathrm{~m}^{3} /\right.$ year) for men and $153 \mathrm{l} /$ day ( $=56 \mathrm{~m}^{3} /$ year) for women. We identified that the consumption of non-alcoholic drinks, fruits and meat are the most important contributors to the total Dutch blue water use. The majority of blue water use for the Dutch diet takes place abroad, in countries where water is relatively scarce. This is, for example, the case for Spain, Egypt and Morocco, and the food products contributing most are (citrus) fruits, vegetables and livestock products (particularly feed). We state that, in most cases, plant based foods have a lower blue water use than animal based foods, but there are exceptions: some plant-based foods (nuts and certain fruits) do have a relatively high blue water use per $\mathrm{kg}$ product. To lower the Dutch blue water use within a healthy diet, reducing meat and dairy consumption, consuming more Dutch fruits like apples and pears, and reducing the consumption of nonalcoholic beverages like coffee, soft drinks and juices (replaced by tap water) is recommended.

\section{References}

[1] FAO. AQUASTAT $<$ http://www.fao.org/nr/water/aquastat/water_use/index.stm> (2016).

[2] Hoekstra, A. Y. \& Mekonnen, M. M. The water footprint of humanity. Proceedings of the national academy of sciences 109, 3232-3237 (2012).

[3] Vanham, D. \& Bidoglio, G. A review on the indicator water footprint for the EU28. Ecological Indicators 26, 61-75 (2013).

[4] Campbell, B. M. et al. Agriculture production as a major driver of the earth system exceeding planetary boundaries. Ecology and Society 22, doi: 10.5751/ES-09595-220408 (2017).

[5] Hoekstra, A. Y. Water footprint assessment: evolvement of a new research field. Water Resources Management 31, 1-21 (2017).

[6] Temme, E. H. et al. Greenhouse gas emission of diets in the Netherlands and associations with food, energy and macronutrient intakes. Public health nutrition 18, 2433-2445 (2015).

[7] Seves, S. M., Verkaik-Kloosterman, J., Biesbroek, S. \& Temme, E. H. Are more environmentally sustainable diets with less meat and dairy nutritionally adequate? Public Health Nutrition 20, 1-13, doi: 10.1017/s1368980017000763 (2017).

[8] Vellinga, R. E. et al. Greenhouse Gas Emissions and Blue Water Use of Dutch Diets and Its Association with Health. Sustainability 11, 6027, doi: 10.3390/su11216027 (2019).

[9] van de Kamp, M. E. et al. Healthy diets with reduced environmental impact? - The greenhouse gas emissions of various diets adhering to the Dutch food based dietary guidelines. Food Research International 104, doi: http://dx.doi.org/10.1016/j.foodres.2017.06.006 (2017). 
[10] Hollander, A., Temme, E. \& Zijp, M. The environmental sustainability of the Dutch diet: Background report to 'What is on our plate? Safe, healthy and sustainable diets in the Netherlands. (The National Institute for Public Health and the Environment, Bilthoven, 2017)

[11] Hoekstra, A., Chapagain, A., Aldaya, M. \& Mekonnen, M. The water footprint assessment manual: Setting the global standard. (Earthscan, 2011).

[12] Vanham, D., Mak, T. \& Gawlik, B. Urban food consumption and associated water resources: The example of Dutch cities. Science of the Total Environment 565, 232-239 (2016).

[13] Vanham, D., Hoekstra, A. Y. \& Bidoglio, G. Potential water saving through changes in European diets. Environment international 61, 45-56 (2013).

[14] Boulay, A.-M. et al. The WULCA consensus characterization model for water scarcity footprints: assessing impacts of water consumption based on available water remaining (AWARE). The International Journal of Life Cycle Assessment 23, 368378 (2018).

[15] Van Rossum, C. et al. The diet of the Dutch: Results of the first two years of the Dutch National Food Consumption Survey 2012-2016. RIVM letter report 2016-0082 (2016).

[16] Slimani, N. et al. Standardization of the 24-hour diet recall calibration method used in the European Prospective Investigation into Cancer and Nutrition (EPIC): general concepts and preliminary results. European journal of clinical nutrition 54, 900-917, doi: 10.1038/sj.ejcn.1601107 (2000).

[17] The National Institute for Public Health and the Environment. (Bilthoven, 2016).

[18] Huijbregts, M. et al. ReCiPe 2016: A harmonized life cycle impact assessment method at midpoint and endpoint level Report I: Characterization. (The National Institute for Public Health and the Environment, Bilthoven, 2016).

[19] Durlinger, B. et al. Agri-Footprint; a Life Cycle Inventory database covering food and feed production and processing. Proceedings of the 9th International Conference LCA of Food, 310-317 (2014).

[20] RIVM. (The National Institute for Public Health and the Environment). LCA database food, $<$ https://statline.rivm.nl/\#/RIVM/nl/dataset/50060NED/table>

[21] Blonk Consultants. Direct Land Use Change Assessment Tool Version 2016.1.; Blonk Consultants: Gouda, The Netherlands,. (2016).
[22] De Boer, E. et al. The European food consumption validation project: conclusions and recommendations. European journal of clinical nutrition 65, S102-S109 (2011).

[23] Westerterp, K. R. \& Goris, A. H. Validity of the assessment of dietary intake: problems of misreporting. Current Opinion in Clinical Nutrition \& Metabolic Care 5, 489-493 (2002).

[24] Pfister, S., Koehler, A. \& Hellweg, S. Assessing the environmental impacts of freshwater consumption in LCA. Environmental science \& technology 43, 4098-4104 (2009).

[25] Van Oel, P., Mekonnen, M. \& Hoekstra, A. Y. The external water footprint of the Netherlands: Geographically-explicit quantification and impact assessment. Ecological Economics 69, 82-92 (2009).

[26] Harris, F. et al. The Water Footprint of Diets: A Global Systematic Review and Meta-analysis. Advances in Nutrition: An International Review Journal, 1-12 (2019).

[27] Meier, T. \& Christen, O. Environmental impacts of dietary recommendations and dietary styles: Germany as an example. Environmental science \& technology 47, 877-888 (2012).

[28] Tom, M. S., Fischbeck, P. S. \& Hendrickson, C. T. Energy use, blue water footprint, and greenhouse gas emissions for current food consumption patterns and dietary recommendations in the US. Environment Systems and Decisions 36, 92-103, doi: 10.1007/s10669-015-9577-y (2016).

[29] Willett, W. et al. Food in the Anthropocene: the EAT-Lancet Commission on healthy diets from sustainable food systems. The Lancet 393, 447-492 (2019).

[30] Aleksandrowicz, L., Green, R., Joy, E. J., Smith, P. \& Haines, A. The impacts of dietary change on greenhouse gas emissions, land use, water use, and health: a systematic review. PloS one 11, doi: 10.1371/journal.pone.0165797 (2016).

[31] Jalava, M., Kummu, M., Porkka, M., Siebert, S. \& Varis, O. Diet change - a solution to reduce water use? Environmental research letters 9, 074016 (2014).

[32] Davis, K. F. et al. Meeting future food demand with current agricultural resources. Global Environmental Change 39, 125132 (2016).

[33] Vanham, D., Mekonnen, M. M. \& Hoekstra, A. Y. Treenuts and groundnuts in the EAT-Lancet reference diet: Concerns regarding sustainable water use. Global food security 24, 100357 (2020). 